\title{
Clinical manifestations and treatment outcomes in HIV-1-infected children receiving antiretroviral therapy in Karachi, Pakistan
}

\author{
Fatima Mir ${ }^{1}$, Farah Naz Qamar ${ }^{1}$, Naila Baig-Ansari², Azra Ghayas Abro³, Syed Qamar Abbas ${ }^{4}$, \\ Mohammad Ahmed Kazi ${ }^{4}$, Arjumand Rizvi ${ }^{1}$, Anita KM Zaidi ${ }^{1}$ \\ ${ }^{1}$ Department of Pediatrics and Child Health, The Aga Khan University, Karachi, Pakistan \\ ${ }^{2}$ Research Faculty, Indus Hospital Research Center, The Indus Hospital, Karachi, Pakistan \\ ${ }^{3}$ Enhanced HIVI AIDS Control Programme, Civil Hospital, Karachi, Pakistan \\ ${ }^{4}$ Enhanced HIVIAIDS Control Program, Sindh, Pakistan
}

\begin{abstract}
Introduction: The impact of antiretroviral (ARV) therapy on immunological and growth parameters in HIV-positive children in Pakistan has not been reported to date.

Methodology: A retrospective chart review of children diagnosed with HIV at the Sindh AIDS Control Proigramme (SACP) and registered at the Aga Khan University, Karachi, between January 2005 and 2013 was conducted, evaluating clinical and laboratory profiles of HIV+ ARV+ children for ARV impact (serial height and weight CD4 and viral counts).

Results: Twenty-four children were diagnosed and registered as HIV positive over five years, and 20 were started on ARV. Six were excluded from analysis (ARV duration $<6$ months). Nine $(64.3 \%)$ of 14 fulfilled WHO criteria for treatment failure at a median duration of 25 weeks (IQR 18-32) on ARV and underwent resistance genotyping. All nine had NNRTI resistance, two had high-grade NRTI resistance ( $\geq 4$ thymidine analog mutations).

Median age at start of ARV was 71.5 weeks (IQR 37.5-119). Median baseline weight for age (WAZ) and height for age (HAZ) z-scores changed from -1.94 to 1.69 and -1.99 to -1.59 , respectively, after six months of therapy. Median CD4 percentage and viral load at baseline changed from 13.8 to 17.8 , while viral load changed from $285 \times 10^{4}$ copies to zero at six months.

Conclusions: ARV improved absolute CD4 and viral counts. Weight and height did not improve significantly, highlighting the need for aggressive nutritional rehabilitation. Early development of ARV resistance in these children requires formal assessment.
\end{abstract}

Key words: pediatric HIV; response; ARV; clinical manifestations; laboratory profile

J Infect Dev Ctries 2014; 8(4):519-525. doi:10.3855/jidc.3782

(Received 10 May 2013 - Accepted 11 July 2013)

Copyright (C) 2014 Mir et al. This is an open-access article distributed under the Creative Commons Attribution License, which permits unrestricted use, distribution, and reproduction in any medium, provided the original work is properly cited.

\section{Introduction}

The advent of antiretroviral therapy in 1996 and the subsequent global scale-up over the following years have significantly reduced morbidity and mortality in HIV-infected children in both developed $[1,2]$ and developing countries [3,4]. Optimizing delivery of ARV to HIV-infected children in resourcelimited countries, however, is fraught with challenges such as poor health care infrastructure, limited availability of pediatric drug formulations, lack of monitoring techniques, and competing public health priorities [5]. The impact of ARV on HIV-positive children in Pakistan in terms of clinical events monitoring (weight gain, disease stage, and functional score) and/or more resource-dependent adherence monitoring (pill counts versus CD4 and PCR for viral load) has not been done since its implementation in
2005 [5]. Factors which may influence clinical outcomes of ARV include drug resistance and toxicity, malnutrition, financial independence, and quality of social support and care (caretakers other than parents).

Known determinants such as age and CD4 percentage at ARV initiation [6] have led to revisions in ARV initiation criteria from a CD4\% threshold of $\leq$ $15 \%$ in 2006 to $\leq 25 \%$ in 2010 [7,8]. Age limit for ARV regardless of CD $4 \%$ is now recommended for all children under 24 months rather than under 12 months as recommended earlier $[7,8]$. These revisions in WHO recommendations are based on data showing better survival, lower morbidity, and improved laboratory parameters with earlier initiation of ARV in children $[9,10]$. Lower morbidity has been studied in several pediatric antiretroviral clinical trials as using composite endpoints, such as time to opportunistic 
infection [11], neurologic deterioration [12], and poor weight growth velocity (three consecutive months with less than the third percentile for age- and genderspecific six-month weight growth velocity) on incremental curves [13] in several pediatric antiretroviral clinical trials. Though reports from developing countries show growth impact in terms of WAZ (by about 1 SD from -2 SD or below at baseline) [14], HAZ and/or WHZ and BMIZ [15-18], HAZ and WAZ may be more appropriate because in HIVinfected children, the disease itself adversely affects growth in a manner which is symmetrical, with equal effects on weight and height $[19,20]$. This is in contrast to non-HIV malnutrition where WHZ is more appropriate because the most common pattern of growth is weight loss relative to height for age, followed by declines in height for age, and finally slowed head circumference growth.

Higher baseline CD4 values and use of NNRTIbased regimens rather than PI-based are two important predictors of faster immunologic recovery [15,21-23].

Key challenges in management of pediatric HIV in Pakistan remain lack of personnel capable of taking care of HIV-infected children, holistic care at one accessible site, identification and accessibility to HIVinfected orphans/vulnerable children, access to laboratory monitoring of therapy at smaller centers, and insufficient funds for auxiliary services such as opportunistic infection screening/therapy, nutritional and occupational rehabilitation for patients, both children and parents. This paper evaluates impact on weight (clinical) and immunological and virological counts (laboratory) in 14 HIV-positive children in Karachi.

\section{Methodology}

Study setting

With an estimated population of 168.79 million by the end of 2009 and an average annual growth rate of $1.9 \%$, Pakistan ranks as the sixth most populous nation in the world. Sindh province is second to Punjab in population and HIV prevalence, housing 4 of 14 HIV treatment centres ( 3 in Karachi, 1 in Larkana).

The infectious disease service at the Department of Pediatrics and Child Health, Aga Khan University (AKU) provides ARV treatment and ambulatory care to 24 of 48 children registered with the Sindh AIDS Control Program (SACP) as of January 2013. Consultation and ARV are provided free of cost. Care for the family remains geographically fragmented with pediatric care (including ARV) both at AKU and Civil Hospital, parental care at Civil/Indus Hospital, Karachi
(20 kilometers apart) and laboratory facility at the SACP-designated Molecular Diagnostics and Immunology Laboratory, Sindh Institute of Urology and Transplantation (SIUT). Family visits require coordination of laboratory working hours, physician availability, and patient feasibility at all sites.

Antiretroviral therapy and prognostic tests such as CD4 and viral load are provided free of cost by the National AIDS Control Programme, Ministry of Health, Pakistan. T-cell counts are quantitated by flow cytometry procedures (Multiset, Becton-Dickenson). Plasma HIV RNA quantitation is performed using the NASBA HIV-1 RNA QT Amplification System (Organon Teknika Corp, Durham, NC, USA). Viral load is reported as copies $/ \mathrm{mL} \quad(<50$ copies $/ \mathrm{mL}$ is reported as undetected). HIV-1 Genotyping for drug resistance, based on DNA sequencing technology to analyze the protease and reverse transcriptase genes for mutations reported to confer resistance to antiretroviral therapy, is performed for patients with clinical and immunological or virological failure.

\section{Data collection and analysis}

Clinical and laboratory records of patients fulfilling study criteria $(\leq 15$ years of age and HIV+ and on $A R V \geq 6$ months) during the study period were retrieved from the Medical Records Department at AKU. Clinical parameters assessed were age, gender, height and weight, stage of disease at presentation, and CD4\% and viral load (at diagnosis, at the start of ARV and at six-month, one-year, two-year and three-year intervals post-initiation). Medians and frequencies were analyzed using SPSS version 17.0 (SPSS, Chicago, IL, USA). Weight for age, height for age, and BMI for age z-scores were calculated using WHO Anthro and Anthro plus software (version 3.2.2). The non-parametric Mann-Whitney $U$ test was used to compare growth and immunological parameters between two subgroups of patients (those with and without resistance genes).

\section{Results}

Of 14 children included in analysis, at the time of diagnosis, six (42.9\%) had WHO clinical stages 3-4, eight (77.1\%) were ARV-eligible per the 2006 guidelines at time of diagnosis, and thirteen were ARV-eligible $(92.9 \%)$ by the 2010 recommendations. All children had received multiple doses of live viral polio vaccination during routine (four in the first year of life) and supplementary immunizations (five to six rounds per year) and BCG at birth without any adverse effects. Five patients belonged to cities/towns outside 
Karachi (range of 160-450 kilometers) and had major difficulties making regular follow-up visits. Half of the patients $(n=7)$ had lost one or more parent to the disease at the time of diagnosis. Vertical transmission was the primary mode of acquisition $(n=12,85.7 \%)$.

Median WAZ and HAZ at baseline are given in Table 1. Lag between diagnosis and start of ARV (Table 1) was due to parental reluctance in four (28.5\%) patients.

Median CD4 count/percentage and viral load at baseline are given in Table 1. All patients were started on first-line ARV composed of zidovudine, lamivudine, and nevirapine. Only one (7.1\%) patient had severe zidovudine-related headache and anemia requiring replacement of zidovudine with alternate NRTI tenofovir.

Table 2 shows the changes in WAZ and HAZ over 6 months, 1 year, 18 months, and 3 years of ARV. There was a statistically significant difference in CD4 count and percentage at 18 months between 10 patients with subsequent resistance and 4 who remained susceptible until the end of the study period $(\mathrm{U}=0, \mathrm{p}=0.044)$.

Table 1. Baseline demographics and WHO clinical stage of HIV at initial registration of 14 HIV-infected patients who received ART

\begin{tabular}{|c|c|}
\hline Baseline characteristics & No. Patients (\%) \\
\hline Male & $9(64.3 \%)$ \\
\hline Percentage residing $>70 \mathrm{~km}$ away from center of care & $5(35.7 \%)$ \\
\hline \multicolumn{2}{|l|}{ WHO stage at time of diagnosis } \\
\hline Stage 1 & $2(14.3 \%)$ \\
\hline Stage 2 & $6(42.9 \%)$ \\
\hline Stage 3 & $5(35.7 \%)$ \\
\hline Stage 4 & $1(7.1 \%)$ \\
\hline Median age at diagnosis (IQR), months & $52.5(27.8-98)$ \\
\hline Median age at ART start (IQR), months & $71.5(37.5-119)$ \\
\hline Lag between HIV diagnosis and ART start in months, median (IQR) & $22(3.8-35.5)$ \\
\hline \multicolumn{2}{|l|}{ Children $<5$ years of age at ART start } \\
\hline Weight for age Z-score (WAZ) & $-1.94(-3.35$ to -1.48$)$ \\
\hline Height for age Z-score (HAZ) & $-1.99(-3.21$ to -0.82$)$ \\
\hline BMI Z-score (BAZ) & $-1.12(-2.21$ to -0.62$)$ \\
\hline CD4 at baseline, median (IQR) & $233.5(178.5-352.7)$ \\
\hline CD4 percentage at baseline, median (IQR) & $13.8(9.3-19.6)$ \\
\hline \multicolumn{2}{|l|}{ CD4 percentage at baseline } \\
\hline$<15 \%$ & $8(57.1 \%)$ \\
\hline $15-25 \%$ & $5(35.7 \%)$ \\
\hline$>25 \%$ & $1(7.1 \%)$ \\
\hline Percentage of children with viral load performed at baseline & $8(57.1 \%)$ \\
\hline Viral load at baseline, $10^{4}$ copies, median (IQR) & $285(18.5-475)$ \\
\hline Percentage of children with vertically acquired disease & $12(85.7 \%)$ \\
\hline \multicolumn{2}{|l|}{ Parental status of children with vertically acquired disease ${ }^{\S}$} \\
\hline Both alive & $7(50 \%)$ \\
\hline One parent dead & $5(35.7 \%)$ \\
\hline Both parents dead & $2(14.3 \%)$ \\
\hline Percentage of children who showed treatment failure & $9(64.3 \%)$ \\
\hline Percentage of children who underwent resistance genotyping, $n=14$ & $9(64.3 \%)$ \\
\hline \multicolumn{2}{|l|}{ Common resistance genotype identified, $\mathrm{n}=9$} \\
\hline \multicolumn{2}{|l|}{ NRTI } \\
\hline 184V (decreased susceptibility to lamivudine) & $8(88.9 \%)$ \\
\hline$\geq 4$ thymidine analogue mutations (TAMs) & $2(22.2 \%)$ \\
\hline Pathway 1 (high zidovudine resistance, high NRTI cross-resistance) & $4(44.4 \%)$ \\
\hline Pathway 2 (more NRTI cross-resistance) & $3(33.3 \%)$ \\
\hline NNRTI (Major) & $9(100 \%)$ \\
\hline$P I$ & $1(11.1 \%)$ \\
\hline Duration ARV at time of treatment failure in months, median (IQR) & $25(18-32)$ \\
\hline
\end{tabular}


Table 2: Impact of antiretroviral therapy on growth, immunological and virological parameters $(\mathrm{n}=14)$

\begin{tabular}{|c|c|c|c|c|c|}
\hline Characteristic & BL & 6 months & 1 year & 18 months & 3 years \\
\hline & $\mathrm{n}=14$ & $\mathrm{n}=12$ & $\mathrm{n}=10$ & $\mathrm{n}=11$ & $\mathrm{n}=6$ \\
\hline \multicolumn{6}{|l|}{ Growth parameters } \\
\hline WAZ Median (IQR) & $-1.94(-3.35$ to -1.48$)$ & $1.69(-3.05$ to -0.89$)$ & $-1.36(-3.4$ to -0.94$)$ & $-1.525(-2.82$ to -0.12$)$ & $-1.58(-1.6$ to 0.21$)$ \\
\hline HAZ Median (IQR) & $-1.99(-3.21$ to -0.82$)$ & $-1.59(-3.07$ to -0.63$)$ & $-1.77(-3.03$ to -0.86$)$ & $-1.64(-2.98$ to -0.73$)$ & $-1.36(-2.76$ to -0.39$)$ \\
\hline BAZ Median (IQR) & $-1.12(-2.21$ to -0.62$)$ & $-1.45(-1.88$ to -0.17$)$ & $-1.45(-1.99$ to -0.53$)$ & $-0.89(-1.78$ to +0.36$)$ & $-1.05)-2.84$ to -0.93$)$ \\
\hline$\%<-2$ SD WAZ (underweight) & 6 of $14(42.9 \%)$ & 4 of $12(28.6 \%)$ & 4 of $14(28.6 \%)$ & 3 of $12(21.4 \%)$ & 0 of $7(0 \%)$ \\
\hline$\%<-2$ SD HAZ (stunted) & 7 of $14(50 \%)$ & 6 of $12(42.9 \%)$ & 6 of $14(42.9 \%)$ & 5 of $12(41.7 \%)$ & 2 of $7(28.6 \%)$ \\
\hline$\%<-2$ SD WHZ (wasted) & 4 of $14(28.6 \%)$ & 3 of $12(21.4 \%)$ & 3 of $14(0.1 \%)$ & 2 of $12(16.7 \%)$ & 2 of $7(28.6 \%)$ \\
\hline CD4, median (IQR) & $233.5(178.5-352.7)$ & $407(317.8-832.3)$ & $685(356.5-1057)$ & $734(238-1180)$ & $950.8(478.5-1428.5)$ \\
\hline CD4\%, median (IQR) & $13.8(9.3-19.6)$ & $17.8(12.2-26.8)$ & $22.6(18.2-32.8)$ & $22.4(22.4-39.4)$ & $28.3(24.6-35.8)$ \\
\hline $\begin{array}{l}\text { Proportion of children with CD } 4 \% \\
\text { below } 25 \%\end{array}$ & $13 / 14$ & $7 / 10$ & $5 / 9$ & $7 / 9$ & $1 / 6$ \\
\hline $\begin{array}{l}\text { Median viral load before ART start, } \\
10^{2} \text { copies }\end{array}$ & $28,500(1850-47,500)$ & $0(0-600)$ & $1,800(0-21,250)$ & $2,000(0-50,000)$ & $200(0-1,250)$ \\
\hline \multicolumn{6}{|l|}{ Proportion with } \\
\hline$<50$ copies $/ \mathrm{mL}$ & 0 of 8 & 6 of 11 & 3 of 10 & 3 of 11 & 2 of 6 \\
\hline$<400$ copies $/ \mathrm{mL}$ & 0 of 8 & 2 of 11 & 1 of 10 & 0 of 11 & 2 of 6 \\
\hline$>100000$ copies $/ \mathrm{mL}$ & 7 of 8 & 1 of 11 & 0 of 10 & 2 of 11 & 0 of 6 \\
\hline$>1000$ copies $/ \mathrm{mL}$ & 8 of 8 & 2 of 11 & 5 of 10 & 6 of 11 & 1 of 6 \\
\hline
\end{tabular}


Nine children showed signs of treatment failure at a median period of 25 months (18-32) of starting ARV. Reasons for clinical failure were evident in four patients (three with gross non-compliance, one thalassemic with hyperferritinemia and hypersplenism) alone. All nine were genotyped for ARV resistance genes; all nine had one major NNRTI resistance mutation precluding the use of nevirapine (K103N, G190A, Y188L, or Y181C). Only two had high-grade NRTI resistance ( $\geq 4$ thymidine analogue mutations [TAMs]); four had pathway 1 TAMs (T215Y/F, L210W), and three had pathway 2 TAMs (D67G/N, K70R, K219E/Q) (Table 1). Immunological and growth parameters improved after adjusting to secondline ARV (lopinavir/ritonavir) and alternate NRTIs (tenofovir or didanosine).

\section{Discussion}

We found poor nutritional recovery in almost half of our patients despite appropriate ART and micronutrient supplementation. The age at time of diagnosis correlated approximately to parental diagnosis following sentinel illnesses in the children's fathers. The delay in starting ARV could be attributed mainly to parental reluctance to take up responsibility for patient compliance at the time of diagnosis despite clinical indication.

All children showed a 6 log decrease in viral counts at six months. Successful virological response has been reported variously, as $<50[15,23],<400$ $[16,21,24]$ or $<1000$ copies/mL [25] in different parts of the world. Based on these cut-offs, response rates of 55\% (two months) in China [24], 74\% in Cambodia [16], and 69\% (three months) and 70\% (two years) in Thailand have been reported [15].

Bunupuradah et al. [26] defined virological failure as plasma HIV RNA level $>1000$ copies $/ \mathrm{mL}$ after at least 24 weeks of treatment. WHO defines $>1000$ copies $/ \mathrm{mL}$ based on two consecutive viral load measurements after at least six months on ARV, with adherence support predictive of virological failure and $>100,000$ copies $/ \mathrm{mL}$ predictive of AIDS-defining events $[7,8]$. In Karachi, the proportion of children with viral suppression $(<50$ copies $/ \mathrm{mL})$ at 1 year, 18 months, 2 years, and 3 years progressively decreased after initial suppression at 6 months, indicating treatment failure at a median of 25 months of ARV. Imminent resistance at 18 months and beyond on ARV was suggested by WHO resistance indicators such as on-time drug pick-up of $<90 \%$ and on-time ART clinic appointment-keeping of $<80 \%$ [8]. Adherence to follow-up visit schedules and clinical monitoring of
5 of $14(35.1 \%)$ patients residing outside Karachi remained sub-optimal, with approximate intervals between visits as far as one to one-and-a-half years apart in contrast to three to four months between visits for the remaining nine. Travel expenses per visit could have been a limiting factor for out-station patients travelling into Karachi from other areas of Sindh (USD 50-100 versus USD 2.5-5 for city residents) . Capacity building in terms of training pediatricians to supervise pediatric HIV care in Larkana (450 kilometers from Karachi) is now underway.

The CD4 percentages were at a median of 13.8 and reached values close to $25 \%$ in almost 18 months. This is consistent with data from the pediatric antiretroviral clinical trials group (PACTG) where only $36 \%$ of 1,236 children with $\mathrm{CD} 4 \%<15 \%$ at baseline achieved $\mathrm{CD} 4 \% \geq 25 \%$ after five years of HAART compared with $59 \%$ of children whose baseline CD4\% ranged between 15\%-24\% [6,27]. Other Asian cohorts have reported a more significant increase of $12 \%-27 \%$ in CD4\% and viral load suppression in $55 \%-85 \%$ at one year after ARV [25].

Nachman et al. [28] reported a faster weight gain in children with higher baseline viral load counts. Baseline growth parameters in our cohort were worse than reported from the United States $[28,29]$ and Spain [30] but similar to those reported from Thailand [10] and India [31]. Aurbipol et al. report higher entry WAZ and HAZ, use of nevirapine-based regimen rather than efavirenz, and larger CD4\% gains to week 48 as predictors of growth reversal after initiating ARV [32]. Our patients, though on nevirapine-based regimens, had poorer growth recovery at 6 and 18 months compared to patients in other developing countries [33]. Though lack of an aggressive nutritional rehabilitation may have played a role, the possible confounding effect of developing resistance was accounted for by running the non-parametric Mann-Whitney $U$ test to compare growth and immunological parameters between two sub-groups of patients ( 4 who remained susceptible until the end of the study period and 10 with treatment failure). There was no significant difference in values of WAZ/HAZ and viral load (VL) at 6, 12, 18, 24, 30, and 36 months of ARV in both groups. Drug-related anorexia was another common finding in our patients together with sub-optimal adherence to micro- and macronutrient supplementation. Earlier initiation of ARV (at CD4\% $<25$ ), regular follow-up visits for all patients, and supervised nutritional supplementation could have been associated with earlier growth and immunological recovery in our patients. Conversely, 
CD4 counts and percentages were significantly higher in the group with no resistance at 18 months, after which it became comparable to those in the resistant group, probably due to improved clinical response after initiation of second-line therapy in the resistant group. Studies now show improved height and weight recovery with vitamin A supplementation [34], with B-complex and mineral supplementation [35], and protease-inhibitor (PI) containing regimens [22].

Financial constraints were a major hurdle in managing nutritional supplementation and additional medication needs in our patients during outpatient visits. A variety of auxiliary services (nutrition, travel, occupational/vocational training) available for patients through private sector (NGOs) are not systematically channeled through the national program platform, leading to a lack of awareness among caregivers as a group and therefore under-utilization of available resources by patients. Liaisons between medical and paramedical services must be optimized.

All patients tested for resistance on the basis of virological non-response had received nevirapinebased ARV. Jittamala et al. reported poor adherence in the first 48 weeks of ARV and nevirapine-based rather than efavirenz-based regimens as predictive of virological failure [36]. Lower weight and height $\mathrm{z}$ scores at the onset of treatment, age less than three years, and delay in switching from first- to second-line therapy have also been reported as predictors of virological failure [37]. Policy revisions regarding resistance testing prior to starting ARV and using PIbased ARV for treatment-naïve children instead of NNRTI-based ARV will have to be based on further study of the determinants of ARV resistance in our population.

\section{Acknowledgements}

Drs Fatima Mir and Farah Naz received research training support from the National Institute of Health's Fogarty International Center (1 D43 TW007585-01). We would like to thank Dr Imran Nisar for his help with statistical tests.

\section{References}

1. Viani RM, Araneta MR, Deville JG, Spector SA (2004) Decrease in hospitalization and mortality rates among children with perinatally acquired HIV type 1 infection receiving highly active antiretroviral therapy. Clin Infect Dis 39: 725-731.

2. Chiappini E, Galli L, Tovo PA, Gabiano C, Gattinara GC, Guarino A, Badolato R, Giaquinto C, Lisi C, de Martino M (2006) Virologic, immunologic, and clinical benefits from early combined antiretroviral therapy in infants with perinatal HIV-1 infection. AIDS 20: 207-215.

3. Puthanakit T, Aurpibul L, Oberdorfer P, Akarathum N, Kanjananit S, Wannarit P, Sirisanthana T, Sirisanthana V (2007) Hospitalization and mortality among HIV-infected children after receiving highly active antiretroviral therapy. Clin Infect Dis 44: 599-604.

4. Bolton-Moore C, Mubiana-Mbewe M, Cantrell RA, Chintu N, Stringer EM, Chi BH, Sinkala M, Kankasa C, Wilson CM, Wilfert CM, Mwango A, Levy J, Abrams EJ, Bulterys M, Stringer JS (2007) Clinical outcomes and CD4 cell response in children receiving antiretroviral therapy at primary health care facilities in Zambia. JAMA 298:1888-1899.

5. Paintsil E (2011) Monitoring Antiretroviral Therapy in HIVInfected Children in Resource-Limited Countries: A Tale of Two Epidemics. AIDS Res Treat 2011: Article ID 280901.

6. Puthanakit $\mathrm{T}$, Kerr S, Ananworanich J, Bunupuradah T, Boonrak P, Sirisanthana V (2009) Pattern and predictors of immunologic recovery in human immunodeficiency virusinfected children receiving non-nucleoside reverse transcriptase inhibitor-based highly active antiretroviral therapy. Pediatr Infect Dis J 28: 488-492.

7. World Health Organization (2013) Consolidated Guidelines on the use of Antiretroviral Drugs for Treating and Preventing HIV Infection: Recommendations for a public health approach June 2013. Available: http://apps.who.int/iris/bitstream/10665/85321/1/9789241505 727 eng.pdf Accessed 8 February 2014.

8. World Health Organization (2010) Antiretroviral Therapy for HIV infection in infants and children: towards universal access. Recommendations for a public health approach - 2010 revision.

Available: http://whqlibdoc.who.int/publications/2010/9789241599801 eng.pdf Accessed 3 March 2013.

9. Becquet R, Mofenson LM (2008) Early antiretroviral therapy of HIV-infected infants in resource-limited countries: possible, feasible, effective and challenging. AIDS 22: 13651368.

10. Chearskul P, Chokephaibulkit K, Chearskul S, Phongsamart W, Plipat N, Lapphra K, Vanprapar N (2005) Effect of antiretroviral therapy in human immunodeficiency virusinfected children. J Med Assoc Thai 88 Suppl 8: S221-231.

11. Candiani TM, Pinto J, Cardoso CA, Carvalho IR, Dias AC, Carneiro M, Goulart EA (2007) Impact of highly active antiretroviral therapy (HAART) on the incidence of opportunistic infections, hospitalizations and mortality among children and adolescents living with HIV/AIDS in Belo Horizonte, Minas Gerais State, Brazil. Cad Saude Publica 23 Suppl 3: S414-423.

12. Le Doare K, Bland R, Newell ML (2012) Neurodevelopment in children born to HIV-infected mothers by infection and treatment status. Pediatrics 130: e1326-1344.

13. Carey VJ, Yong FH, Frenkel LM, McKinney RE (1998) Pediatric AIDS prognosis using somatic growth velocity. AIDS 12: 1361-1369.

14. Sutcliffe CG, van Dijk JH, Bolton C, Persaud D, Moss WJ (2008) Effectiveness of antiretroviral therapy among HIVinfected children in sub-Saharan Africa. Lancet Infect Dis 8: 477-489.

15. Puthanakit T, Oberdorfer A, Akarathum N, Kanjanavanit S, Wannarit P, Sirisanthana T, Sirisanthana V (2005) Efficacy of highly active antiretroviral therapy in HIV-infected children 
participating in Thailand's National Access to Antiretroviral Program. Clin Infect Dis 41: 100-107.

16. Janssens B, Raleigh B, Soeung S, Akao K, Te V, Gupta J, Chhy Vun M, Ford N, Nouhin J, Nerrienet E (2007) Effectiveness of highly active antiretroviral therapy in HIVpositive children: evaluation at 12 months in a routine program in Cambodia. Pediatrics 120: e1134-1140.

17. O'Brien DP, Sauvageot D, Zachariah R, Humblet P (2006) In resource-limited settings good early outcomes can be achieved in children using adult fixed-dose combination antiretroviral therapy. AIDS 20: 1955-1960.

18. Kumarasamy N, Vallabhaneni S, Flanigan TP, Balakrishnan P, Cecelia A, Carpenter CC, Solomon S, Mayer KH (2005) Rapid viral load suppression following generic highly active antiretroviral therapy in Southern Indian HIV-infected patients. AIDS 19: 625-627.

19. Benjamin Jr DK, Miller WC, Benjamin DK, Ryder RW, Weber DJ, Walter E, McKinney RE (2003) A comparison of height and weight velocity as a part of the composite endpoint in pediatric HIV. AIDS 17: 2331.

20. McKinney RE (1993) Effect of human immunodeficiency virus infection on the growth of young children. Duke Pediatric AIDS Clinical Trials Unit. J Pediatr 123: 579-582.

21. Puthanakit T, Aurpibul L, Sirisanthana T, Sirisanthana V (2009) Efficacy of non-nucleoside reverse transcriptase inhibitor-based highly active antiretroviral therapy in Thai HIV-infected children aged two years or less. Pediatr Infect Dis J 28: 246-248.

22. Soh CH, Oleske JM, Brady MT, Spector SA, Borkowsky W, Burchett SK, Foca MD, Handelsman E, Jimenez E, Dankner WM, Hughes MD (2003) Long-term effects of proteaseinhibitor-based combination therapy on CD4 T-cell recovery in HIV-1-infected children and adolescents. Lancet 362: 2045-2051.

23. Puthanakit T, Aurpibul L, Oberdorfer P, Akarathum N, Kanjanavanit S, Wannarit P, Sirisanthana T, Sirisanthana V (2007) Sustained immunologic and virologic efficacy after four years of highly active antiretroviral therapy in human immunodeficiency virus infected children in Thailand. Pediatr Infect Dis J 26: 953-956.

24. Zhang F, Haberer JE, Zhao Y, Dou Z, Zhao H, He Y, Cao GH (2007) Chinese pediatric highly active antiretroviral therapy observational cohort: a 1-year analysis of clinical, immunologic, and virologic outcomes. J Acquir Immune Defic Syndr 46: 594-598.

25. Bunupuradah T, Aurpibul L, Ananworanich J, Puthanakit T (2009) The effectiveness of highly active antiretroviral therapy among HIV-infected children in Asian countries. Asian Biomedicine 3: 89-100.

26. Bunupuradah $\mathrm{T}$, Puthanakit $\mathrm{T}$, Kosalaraksa $\mathrm{P}$, Kerr $\mathrm{S}$, Boonrak P, Prasitsuebsai W, Lumbiganon P, Mengthaisong T, Phasomsap C, Pancharoen C, Ruxrungtham K, Ananworanich J (2011) Immunologic and virologic failure after first-line NNRTI-based antiretroviral therapy in Thai HIV-infected children. AIDS Research and Therapy 8: 40.

27. Patel K, Hernan MA, Williams PL, Seeger JD, McIntosh K, Van Dyke RB, (2008) Long-term effects of highly active antiretroviral therapy on CD4+ cell evolution among children and adolescents infected with HIV: 5 years and counting. Clin Infect Dis 46: 1751.

28. Nachman SA, Lindsey JC, Moye J, Stanley KE, Johnson GM, Krogstad PA, Wiznia AA (2005) Growth of human immunodeficiency virus-infected children receiving highly active antiretroviral therapy. Pediatr Infect Dis J 24: 352-357.

29. Missmer SA, Spiegelman D, Gorbach SL, Miller TL (2000) Predictors of Change in the Functional Status of Children With Human Immunodeficiency Virus Infection. Pediatrics 106: e24.

30. Guillen S, Ramos JT, Resino R, Bellon JB, Munoz MA (2007) Impact on Weight and Height With the Use of HAART in HIV-Infected Children. Pediatr Infect Dis J 26: 334-338.

31. Poorana Ganga Devi N, Chandrasekaran K, Bhavani PK, Thiruvalluvan C, Swaminathan S (2011) Persistence of stunting after highly active antiretroviral therapy in HIVinfected children in South India. Indian Pediatrics 48: 333.

32. Aurbipol L, Puthanakit T, Taecharoenkul S, Sirisanthana T, Sirisanthana V (2009) Reversal of growth failure in HIVinfected Thai children treated with non-nucleoside reverse transcriptase inhibitor-based antiretroviral therapy. AIDS Patient Care STDS 23: 1067-1071.

33. Ciaranello AL, Chang Y, Margulis AV, Bernstein A, Bassett IV, Losina E, Walensky RP (2009) Effectiveness of pediatric antiretroviral therapy in resource-limited settings: a systematic review and meta-analysis. Clin Infect Dis 49: 1915-1927.

34. Villamor E, Mbise R, Spiegelman D, Hertzmark E, Fataki M, Peterson KE, Ndossi G, Fawzi WW (2002) Vitamin A supplements ameliorate the adverse effect of HIV-1, malaria, and diarrheal infections on child growth. Pediatrics 109: E6.

35. Drain PK, Kupka R, Mugusi F, Fawzi WW (2007) Micronutrients in HIV-positive persons receiving highly active antiretroviral therapy. Am J Clin Nutr 85: 333-345.

36. Jittamala P, Puthanakit T, Chaiinseeard S, Sirisanthana V (2009) Predictors of virologic failure and genotypic resistance mutation patterns in thai children receiving non-nucleoside reverse transcriptase inhibitor-based antiretroviral therapy. Pediatr Infect Dis J 28: 826-830.

37. Bacha T, Tilahun B, Worku A (2012) Predictors of treatment failure and time to detection and switching in HIV-infected Ethiopian children receiving first line anti-retroviral therapy. BMC Infect Dis 12: 197.

\section{Corresponding author}

Fatima Mir, MBBS, FCPS, MSCR

Assistant Professor, In charge Pediatric HIV Treatment and ARV Center

Department of Pediatrics and Child Health, Aga Khan University

Stadium Road PO Box 3500, Karachi 74800, Pakistan

Tel: (92 21) 4930051 Ext 4955

Fax: (92 21) 493-4294, 493-2095

Email: fatima.mir@aku.edu

Conflict of interests: No conflict of interests is declared. 